\title{
Likelihood of Distal Ureteric Calculi to Pass Spontaneously: Systematic Review and Cumulative Analysis of the Placebo Arm of Randomized-Controlled Trials
}

\author{
Emily Pearce $^{\mathrm{a}}$ Keiran D. Clement ${ }^{\mathrm{b}}$ Sachin Yallappa ${ }^{\mathrm{c}}$ Omar M. Aboumarzouk ${ }^{d}$ \\ aDepartment of Paediatric Surgery, Royal Hospital for Children, Glasgow, UK; b Department of Urology, \\ Royal Alexandra Hospital, Paisley, UK; 'Department of Urology, Queen Elizabeth Hospital, Birmingham, UK; \\ dDepartment of Surgery, Hamad General Hospital, Hamad Medical Corporation, Doha, Qatar
}

\begin{abstract}
Keywords
Ureteric calculi · Conservative management · Urolithiasis .

Urinary stones
\end{abstract}

\begin{abstract}
Introduction: Distal ureteric calculi remain a widely debated topic without clear consensus on expectant management. This systematic review aims to assess the placebo arms of RCTs to extrapolate data on the natural history of distal ureteral stones and ascertain the success rate of expectant management. Methods: A literature search was performed, and 3 reviewers used a predefined inclusion criterion to independently select articles for inclusion. A cumulative analysis was undertaken, and risk of bias assessed using the Cochrane tool. Results: Stone expulsion was recorded in 1,823/2,447 (74.5\%) patients overall. The expulsion rate of study participants receiving placebo varied widely from 35.2 to $88.9 \%$. The overall expulsion rate of stones $\leq 5 \mathrm{~mm}$ was $486 / 561$ $(87 \%)$ as opposed to $814 / 1,093(75 \%)$ in stones $>5 \mathrm{~mm}$ in size. Time to stone expulsion varied from 8.54 to 24.5 days. A re rate of $2 \%$ was reported. Conclusions: Spontaneous passage of distal ureteric calculi is dependent on stone size and location within the ureter. Provided a patient does not portray symptoms of uncontrollable pain, infection, obstruction, or declining renal function, it is reasonable to trial a pe-
\end{abstract}

karger@karger.com www.karger.com/uin

Karger $\stackrel{\text { ' }}{5}$

GOPEN ACCESS
(C) 2020 The Author(s)

Published by S. Karger AG, Basel

This article is licensed under the Creative Commons AttributionNonCommercial-NoDerivatives 4.0 International License (CC BY NC-ND) (http://www.karger.com/Services/OpenAccessLicense) Usage and distribution for commercial purposes as well as any distribution of modified material requires written permission. riod of expectant management. Follow-up should be arranged to ensure symptom resolution, and alternative treatment can be offered if required.

(C) 2020 The Author(s)

Published by S. Karger AG, Basel

\section{Introduction}

Urolithiasis is a very common health problem worldwide with both the incidence and prevalence increasing [1]. Worldwide, the prevalence varies geographically but is estimated to be 5-9\% in Europe, 7-13\% in North America, and $1-5 \%$ in Asia [2]. Up to $25 \%$ of individuals will experience recurrence [3]. If stones remain in the kidney, they may be asymptomatic. If, however, they migrate into the ureter, patients can experience flank pain, nausea, and haematuria, termed "ureteric colic" [4].

Various options are available for management of ureteric colic, including conservative or expectant management, medical expulsion therapy, and surgical intervention. Choice of management is dependent on various factors, including patient presentation, clinical assessment, and stone characteristics. If appropriate, attempting to

Emily Pearce and Keiran D. Clement are both first authors. 
allow a stone to pass spontaneously negates the risks and costs associated with 1 or more surgical interventions. However, if a stone does not pass following a trial of conservative management, this may lead to infection, deteriorating kidney function, or readmissions due to uncontrolled pain [5].

A large, international, retrospective cohort study recently noted that distal ureteric stones are significantly more likely to pass with conservative management alone compared to stones situated more proximally in the ureter [6]. However, when counselling patients to trial conservative management of their stone, it is crucial to understand the natural history of these patients with respect to the time frame they can be observed for before attempting other interventions.

The current literature is lacking in level 1 evidence for the spontaneous passage rates of distal ureteric stones, and therefore, this systematic review and cumulative analysis will attempt to outline this through assessment of the placebo arms of randomized controlled trials. This will aid clinicians with respect to counselling patients appropriately.

\section{Materials and Methods}

\section{Search Strategy and Study Selection}

This systematic review was conducted according to Cochrane and PRISMA guidelines [7, 8]. A literature search of The US National Library of Medicine's life science database (MEDLINE) (1980 - April 2020), EMBASE (1980 - April 2020), Cochrane Central Register of Controlled Trials - CENTRAL (in The Cochrane Library - 2020), CINAHL (1980 - April 2020), Clinicaltrials.gov, Google Scholar, and individual urological journals was performed. The search was limited to articles published in English only. No limitations were placed on publication type. Reference lists from articles of interest were also examined for inclusion.

The following search terms were utilized: Urolithiasis, Nephrolithiasis, Ureterolithiasis, Ureteric colic, Calculi, Calculus, Stone, Stone passage, Urinary, Ureteric, Kidney, Renal, Bladder, Randomized, Randomised, RCT, Medical expulsive therapy, Conservative, Conservative treatment, Adrenergic alpha-antagonists, and Calcium channel blockers. Medical Subject Heading (MeSH) phrases included ( “Calculi"[Mesh] AND "Urinary Calculi" [Mesh] AND "Kidney Calculi"[Mesh]); ("Adrenergic AlphaAntagonists"[Mesh]) AND "Urinary Calculi”[Mesh]\}.

Three reviewers (EP, KDC, and SY) used predefined inclusion criteria to independently select articles for potential inclusion. Senior author independently cross referenced included studies for inclusion to ratify collective findings. Where there was a lack of consensus, the authors discussed the full text until an agreement was reached with respect to our pre-existing inclusion criteria.

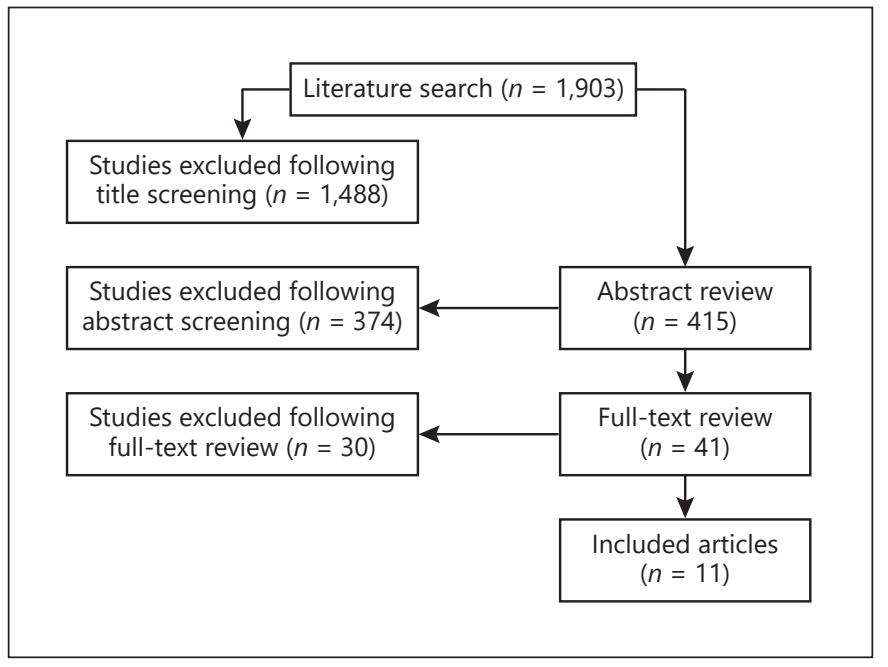

Fig. 1. PRISMA flowchart for article selection process of the review.

\section{Inclusion Criterion}

The objectives of this review were to describe the natural history of distal ureteric stones through assessment of the placebo arm of interventional randomized controlled trials. Trials were only included if participants were provided with a placebo alternative to the active treatment arm, as opposed to merely being included as a non-treatment control arm of the trial. Studies assessing treatment modalities on stones at other anatomical locations of the urinary tract were only included if data were extractable for those patients with distal ureteric calculi alone. Trials assessing children $(<18$ years of age) were excluded.

\section{Data Extraction and Analysis}

The following variables were extracted from each included study: year of publication, country where the study was undertaken, number of patients included in the placebo arm of trial, patient sex, mean stone size, rate of stone expulsion, expulsion rate of stones $\leq 5$ and $>5 \mathrm{~mm}$, mean time to expulsion, and rehospitalization rate.

Extracted data from each included study were presented using Microsoft Excel and results analysed numerically. A cumulative analysis was performed to give a numerical representation of the end results.

\section{Risk of Bias Assessment}

To assess the risk of bias of the selected studies, an assessment of the methodological quality of the RCT was conducted in line with the Cochrane handbook. Utilizing only the information presented in the study report, each trial was evaluated across 7 domains: random sequence generation (selection bias), allocation concealment (selection bias), blinding of participants and personnel (performance bias), blinding of outcome assessors (detection bias), completeness of follow-up (attrition bias), selective reporting (reporting bias), and any other potential biases detected by the review authors during study evaluation. For each domain, each trial was assessed to be at "high," "low," or "unclear" risk of bias. 
Table 1. Reported outcomes and complications of included studies

\begin{tabular}{|c|c|c|c|c|c|c|c|c|}
\hline Study & Study period & Country & $\begin{array}{l}\text { Patients, } \\
n\end{array}$ & $\begin{array}{l}\text { Gender, } \\
\mathrm{M} / \mathrm{F}\end{array}$ & $\begin{array}{l}\text { Age, } \\
\text { years (range) }\end{array}$ & $\begin{array}{l}\text { Spontaneous } \\
\text { stone passage } \\
\text { rate, \% }\end{array}$ & $\begin{array}{l}\text { Mean time } \\
\text { to stone } \\
\text { expulsion, days }\end{array}$ & $\begin{array}{l}\text { Complications (surgical } \\
\text { intervention, hospitalization) }\end{array}$ \\
\hline Abdel-Meguid et al. [9] & $\begin{array}{l}2008-2009 \\
2012-2016\end{array}$ & Saudi Arabia & 75 & $53 / 22$ & $36(19-72)$ & 56 & $\begin{array}{l}\text { Not } \\
\text { documented }\end{array}$ & Not documented \\
\hline Agrawal et al. [10] & $2004-2007$ & India & 34 & $24 / 10$ & $35.3(22-58)$ & 35.2 & 24.5 & Not documented \\
\hline Ahmad et al. [11] & 2010 & Pakistan & 48 & $\begin{array}{l}\text { Not } \\
\text { documented }\end{array}$ & $\begin{array}{l}\text { Not } \\
\text { documented }\end{array}$ & 54.2 & $\begin{array}{l}\text { Not } \\
\text { documented }\end{array}$ & Not documented \\
\hline Al-Ansari et al. [12] & $2007-2009$ & Qatar & 50 & $35 / 15$ & $36.1(21-55)$ & 61 & 9.87 & Surgical intervention $0 \%$ \\
\hline Hermanns et al. [13] & $2006-2008$ & Switzerland & 45 & $36 / 9$ & $41(33-54)$ & 88.9 & 10 & Surgical intervention $4.4 \%$ \\
\hline Meltzer et al. [14] & $\begin{array}{l}2008-2009 \\
2012-2016\end{array}$ & USA & 245 & $373 / 139$ & $39.3(18-74)$ & 47 & $\begin{array}{l}\text { Not } \\
\text { documented }\end{array}$ & $\begin{array}{l}\text { Surgical intervention } 6.9 \% \text {, hospi- } \\
\text { talization } 0.9 \%\end{array}$ \\
\hline Ochoa-Gómez et al. [15] & $2006-2007$ & Mexico & 33 & $\begin{array}{l}\text { Not } \\
\text { documented }\end{array}$ & $\begin{array}{l}38.2 \\
\text { (not documented) }\end{array}$ & 70 & 23 & Surgical intervention $21.2 \%$ \\
\hline Pedro et al. [16] & $2005-2007$ & USA & 35 & $27 / 8$ & $\begin{array}{l}42 \\
\text { (not documented) }\end{array}$ & 77.1 & 8.54 & Surgical intervention $20 \%$ \\
\hline Pickard et al. [17] & $2011-2013$ & UK & 389 & $304 / 85$ & $42.8(18-65)$ & 80 & 15.9 & Not documented \\
\hline Wang et al. [18] & 2011-2014 & Taiwan & 61 & $43 / 18$ & $51.5(28-72)$ & 54.1 & 9.73 & Not documented \\
\hline Ye et al. [19] & $2011-2013$ & China & 1,654 & $1,049 / 605$ & $40.7(18-60)$ & 79 & 10.36 & Not documented \\
\hline
\end{tabular}

\section{Results}

The PRISMA diagram and study selection processed is described in Figure 1. Following the literature search, 1,903 studies were found. 1,488 of these were excluded for not meeting inclusion criteria based upon the title. A further 374 were excluded following review of the abstract leaving 41 articles for full-text assessment. Thirty further studies were excluded for the following reasons: 18 randomized controlled trials did not have a placebo arm, 4 of the studies were prospective cohort studies, 4 were retrospective cohort studies, 1 was a letter to the editor, 1 included only patients with intra-renal calculi, 1 trial did include distal ureteric calculi but did not provide differential expulsion rates for patients dependent on stone location, and 1 study was a case series.

\section{Characteristics of Included Studies}

In total, 11 studies in the published literature were found providing data on patients given placebo as part of a randomized controlled trial investigating management of distal ureteric calculi [9-19]. The basic demographics of each study, as well as reported outcomes and complications are outlined in Table 1.

Two of the studies included were based in the USA, with the remaining studies based in Egypt, India, Pakistan, Oman, Switzerland, Mexico, the UK, Taiwan, and China. All of the included studies were prospective randomized controlled trials investigating the role of some form of medical-expulsive therapy to aid expulsion of ureteric calculi compared to placebo. Ten studies investigated the use of alpha-adrenergic antagonists versus placebo $[9-16,18,19]$. One study was a three-armed trial investigating an alpha-adrenergic antagonist versus a calcium channel blocker versus placebo [17].

Two of the studies focused on medical-expulsive therapy in stones within varying points of the ureter but provided individual data on those within the distal ureter [14, 17]. The remaining 9 studies investigated distal ureteric calculi alone $[9-13,15,16,18,19]$.

Four studies did not provide full basic demographics of study participants $[11,12,14,17]$; however, in 2 of these studies, this was likely due to not only investigating distal ureteric stones [14, 17]. A further 2 studies did not provide data regarding the mean stone size $[11,16]$. Five of the eleven included studies provided data of mean expulsion time of stones $[10,12,13,15,16]$ and 1 provided data on rate of rehospitalization [13].

\section{Cumulative Analysis Results}

In total, 2,447 patients were included in this review, with information on the sex of the included patients being provided in only 1,947 patients $(1,263$ males and $684 \mathrm{fe-}$ males) $[9,10,13,15,16,18,19]$. The mean age of included participants ranged from 35.3 to 51.5 years in the 10 studies providing basic demographics for their included patients $[9,10,12-19]$. 


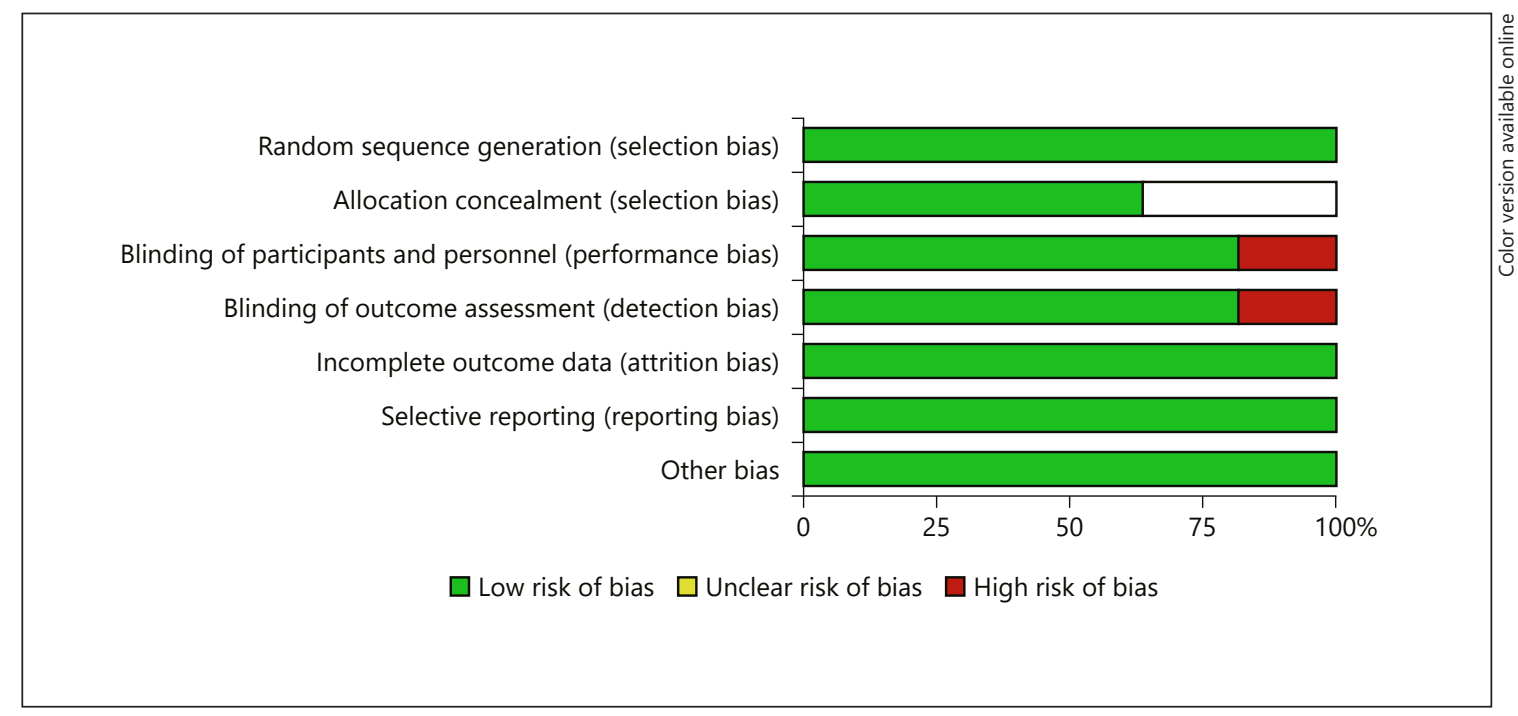

Fig. 2. Risk of bias graph: authors' judgement regarding the risk of bias in each study presented as a percentage across all studies.

\section{Expulsion Rate Overall}

Stone expulsion was recorded in 1,823/2,447 (74.5\%) patients overall. The expulsion rate of study participants receiving placebo varied widely from 35.2 to $88.9 \%$.

\section{Expulsion Rate Dependent on Size}

Only 1 study provided differential data on expulsion rate of stones dependent on size [19]. The overall expulsion rate of stones $\leq 5 \mathrm{~mm}$ was $486 / 561(87 \%)$ as opposed to $814 / 1,093(75 \%)$ in stones $>5 \mathrm{~mm}$ in size.

\section{Mean Time to Expulsion}

Four studies provided mean time to expulsion of calculi in patients receiving placebo and this varied widely from 8.54 to 24.5 days $[10,12,15,16]$.

\section{Rehospitalization Rate}

One study reported a rehospitalization rate during the study period of $2 \%$ ( $1 / 50$ patients) in the placebo arm of their study [13].

\section{Methodological Quality Assessment}

As per our inclusion criterion, all included studies were placebo randomized controlled trials and, therefore, considered to be of high quality. Figure 2 demonstrates a summary of quality assessment based upon the authors' assessment of risk of bias. Seven of the eleven included trials were deemed to be at low risk of bias across all domains [12-14, 16-19].
Four studies did not provide adequate information regarding allocation concealment of their participants and therefore were deemed to be at unclear risk [9-11, 15]. Two studies were considered to be at high risk of bias with respect to blinding of participants and outcome assessment $[10,11]$.

\section{Discussion}

Despite multiple previous studies evaluating the natural history of ureteric stones, the topic of how to best manage distal ureteric calculi in the acute setting remains widely debated among urologists. Commonly used management options include expectant management, medical expulsion therapy, and surgical intervention [20,21]. In order to aid the counselling discussion with patients, we assessed the placebo arms of randomized controlled trials in the management of distal ureteric stones to assess the spontaneous stone passage rates.

\section{Rate of Stone Passage}

Overall, $74.5 \%$ of stones were demonstrated to spontaneously pass. Stone passage was assessed in different ways among included studies. Two studies defined the point of stone passage as the time of participant reporting [10,14], whereas 1 study used non-contrast CT to assess for stone expulsion for up to 28 days following initial presentation [19], and a further study used patient reporting in con- 
junction with imaging (X-ray KUB/ultrasound KUB/noncontrast CT) and review to assess for stone expulsion for up to 14 days following initial presentation [18].

\section{Time to Stone Expulsion}

A total of 4 included studies reported time to stone expulsion. This varied widely from 8.54 to 24.5 days [ $[10,12$, $15,16]$. No studies included in the review reported correlation between stone size and time to stone expulsion. Previous research on time to stone expulsion is limited and linked to stone diameter. A small volume study by Miller and Kane [22] showed that stones up to a diameter for $2 \mathrm{~mm}$ have an average time to expulsion of 8.2 days, while stones of 2-4 mm diameter have an average time to expulsion of 12.2 days and stones with a diameter of 4-6 $\mathrm{mm}$ have an average time to expulsion of 22.1 days. A meta-analysis of 5 studies [23] showed that an estimated $68 \%$ of stones with a diameter of less than $5 \mathrm{~mm}$ would pass spontaneously compared to an estimate of $47 \%$ of stones with a diameter of 6-10 mm. Current EAU [24] and CAU [25] guidelines suggest that around $95 \%$ of stones with a diameter of up to $4-5 \mathrm{~mm}$ are expected to pass within 40 days. This drops to around $50 \%$ for stones with a diameter greater than $5 \mathrm{~mm}$.

\section{Stone Expulsion Rate Dependent on Stone Size}

Only 1 study [19] provided stone expulsion rates relating to the size of the ureteric calculi. This study found that smaller stones were more likely to pass spontaneously when compared to larger stones ( $<5 \mathrm{~mm} 486 / 551$ [87\%],

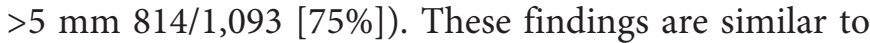
stones in other points of the urinary tract as Shah et al. [6] recently demonstrated. One of our included studies concluded that stones were 3 times more likely to pass spontaneously if they were situated at the ureterovesical junction as opposed to any other part of the distal ureter [13]. Of the 2 studies which looked at stones at multiple levels $[14,17]$, only 1 reported impact of stone position on stone expulsion. This was reported as nonsignificant [14].

\section{Pain Associated with Stone Passage}

Four studies reported a significant increase in number of episodes of pain in patients undergoing expectant management when compared to patients receiving medical-expulsive therapy $[9-11,19]$, while 7 studies reported increased analgesia use in the same patient group [9-13, $18,19]$. Of the 11 trials included, 3 trials reported rehospitalization of patients undergoing expectant management $[11,13,14]$. This was not found to be statistically significant when compared to patients receiving medical

Likelihood of Distal Ureteric Calculi to

Pass Spontaneously expulsion therapy as opposed to placebo. Previous research has shown that patients receiving alpha blockers as medical-expulsive therapy experience significantly fewer episodes of pain and require fewer admission to hospital when compared to placebo [5].

The main limitation of this review is that although all 11 included studies were randomized controlled trials, there were 2 trials $[17,19]$ with a significantly greater proportion of patients than the others, which may have skewed the results. Furthermore, the included studies were heterogeneous or lacking in the way in which they reported outcomes such as time to stone passage, as well as only 1 study providing data on the rate of stone expulsion depending on stone size [19]. Two of the included studies provided little evidence regarding blinding of participants or outcome assessment and, therefore, were deemed to be at high risk of bias overall.

Expectant management of distal ureteric stones remains an option for clinicians treating patients with controlled symptoms in the absence of decline in renal function, obstruction, infection, or severe pain. Results are dependent on the characteristics of the ureteric calculi, most importantly, size and location within the ureter. Smaller stones in the distal ureter have been shown to be the most likely to pass spontaneously. In such cases, it is reasonable to trial a period of expectant management provided follow-up is arranged to ensure patients are not suffering from complications, thereby allowing an alternative treatment to be offered if required. Most studies included in our review showed a higher intake of analgesia or higher reported pain levels; however, there was no statistically significant increase in patient readmissions compared to the interventional arms. Clinicians should determine whether these symptoms are acceptable and supply adequate analgesia if observation without medical expulsion therapy is the elected management strategy.

\section{Conclusions}

Expectant management is a commonly used and viable option for patients with distal ureteric stones. Smaller stones have a higher likelihood of spontaneous passage. This may be associated with an increased number of episodes of pain for the patient, but there was no evidence to suggest in this systematic review that there were increased risks such as development of sepsis or life-threatening renal tract obstruction. These results may be of use in counselling patients with distal ureteric stones. 


\section{Conflict of Interest Statement}

The authors report no conflicts of interest.

\section{Funding Sources}

The authors did not receive any funding.

\section{Author Contributions}

K.D.C. conceived the study proposal. E.P., K.D.C., and S.Y. carried out data collection. E.P. and K.D.C. performed analysis of results and preparation of an initial manuscript. S.Y. and O.M.A. provided manuscript edits. All authors agreed on the final manuscript before submission. E.P. and K.D.C. contributed equally and should be considered as joint first authors. O.M.A. is the manuscript guarantor.

\section{References}

1 Trinchieri A, Coppi F, Montanari E, Del Nero A, Zanetti G, Pisani E. Increase in the prevalence of symptomatic upper urinary tract stones during the last ten years. Eur Urol. 2000;37(1):23-5.

2 Sorokin I, Mamoulakis C, Miyazawa K, Rodgers A, Talati J, Lotan Y. Epidemiology of stone disease across the world. World J Urol. 2017; 35(9):1301-20.

3 Romero V, Akpinar H, Assimos DG. Kidney stones: a global picture of prevalence, incidence, and associated risk factors. Rev Urol. 2010;12(2-3):e86-96.

4 Masarani M, Dinneen M. Ureteric colic: new trends in diagnosis and treatment. Postgrad Med J. 2007;83(981):469-72.

5 Hollingworth J, Canales B, Rogers M, Sukumar S, Yan P, Kuntz GM, et al. Alpha blockers for treatment of ureteric stones: systematic review and meta-analysis. BMJ. 2016;355:i6112.

6 Shah TT, Gao C, Peters M, Manning T, Cashman S, Nambiar A, et al. Factors associated with spontaneous stone passage in a contemporary cohort of patients presenting with acute ureteric colic: results from the multi-centre cohort study evaluating the role of inflammatory markers in patients presenting with acute ureteric. BJU Int. 2019;124(3):504-13.

7 Higgins JP, Thompson SG, Deeks JJ, Altman DG. Measuring inconsistency in meta-analyses. BMJ. 2003;327(7414):557-60.

8 Liberati A, Altman DG, Tetzlaff J, Mulrow C, Gøtzsche PC, Ioannidis JP, et al. The PRISMA statement for reporting systematic reviews and meta-analyses of studies that evaluate health care interventions: explanation and elaboration. PLoS Med. 2009;6(7):e1000100.

9 Abdel-Meguid TA, Tayib A, Al-Sayyad A. Tamsulosin to treat uncomplicated distal ureteral calculi: a double blind randomized placebo-controlled trial. Can J Urol. 2010;17(3): 5178-83.
10 Agrawal M, Gupta M, Gupta A, Agrawal A, Sarkari A, Lavania P. Prospective randomized trial comparing efficacy of alfuzosin and tamsulosin in management of lower ureteral stones. Urology. 2009;73(4):706-9.

11 Ahmad H, Azim W, Akmal M, Murtaza B, Mahmood A, Nadim A, et al. Medical expulsive treatment of distal ureteral stone using tamsulosin. J Ayub Med Coll Abbottabad. 2015;27(1):48-50.

12 Al-Ansari A, Al-Naimi A, Alobaidy A, Assadiq K, Azmi MD, Shokeir AA. Efficacy of tamsulosin in the management of lower ureteral stones: a randomized double-blind placebo-controlled study of 100 patients. Urology. 2010;75(1):4-7.

13 Hermanns T, Sauermann P, Rufibach K, Frauenfelder T, Sulser T, Strebel RT. Is there a role for tamsulosin in the treatment of distal ureteral stones of $7 \mathrm{~mm}$ or less? Results of a randomised, double-blind, placebo-controlled trial. Eur Urol. 2009;56(3):407-12.

14 Meltzer AC, Burrows PK, Wolfson AB, Hollander JE, Kurz M, Kirkali Z, et al. Effect of tamsulosin on passage of symptomatic ureteral stones: a randomized clinical trial. JAMA Intern Med. 2018;178(8):1051-7.

15 Ochoa-Gómez R, Prieto-Díaz-Chávez E, Trujillo-Hernández B, Vásquez C. Tamsulosin does not have greater efficacy than conventional treatment for distal ureteral stone expulsion in Mexican patients. Urol Res. 2011; 39(6):491-5.

16 Pedro RN, Hinck B, Hendlin K, Feia K, Canales BK, Monga M. Alfuzosin stone expulsion therapy for distal ureteral calculi: a doubleblind, placebo controlled study. J Urol. 2008; 179(6):2244-7.
17 Pickard R, Starr K, Maclennan G, Lam T, Thomas R, Burr J, et al. Medical expulsive therapy in adults with ureteric colic: a multicentre, randomised, placebo-controlled trial. Lancet. 2015;386(9991):341-9.

18 Wang CJ, Tsai PC, Chang CH. Efficacy of silodosin in expulsive therapy for distal ureteral stones: a randomized double-blinded controlled trial. Urol J. 2016;13(3):2666-71.

19 Ye Z, Zeng G, Yang H, Tang K, Zhang X, Li $\mathrm{H}$, et al. Efficacy and safety of tamsulosin in medical expulsive therapy for distal ureteral stones with renal colic: a multicenter, randomized, double-blind, placebo-controlled trial. Eur Urol. 2018;73:385-91.

20 Amer T, Osman B, Johnstone A, Mariappan M, Gupta A, Brattis N, et al. Medical expulsive therapy for ureteric stones: analysing the evidence from systematic reviews and metaanalysis of powered double-blinded randomised controlled trials. Arab J Urol. 2017; 15(2):83-93.

21 Somani BK, Aboumarzouk O, Traxer O, Baard J, Kamphuis G, de la Rosette J. Medical expulsive therapy for ureteral stones: where do we go from here? Nat Rev Urol. 2016; 13(10):608-12.

22 Miller OF, Kane CJ. Time to stone passage for observed ureteral calculi: a guide for patient education. J Urol. 1999;162(3 Pt 1):688-1.

23 Preminger GM, Tiselius HG, Assimos DG, Alken P, Buck AC, Gallucci M, et al. 2007 guideline for the management of ureteral calculi. Eur Urol. 2007;52(6):1610-31.

24 Turk A, Neisius A, Petrik C, Seitz C, Skolarikos A, Thomas K, et al. EAU guidelines on urolithiasis. 2020.

25 Ordon M, Andonian S, Blew B, Schuler T, Chew B, Pace KT. CUA guideline: management of ureteral calculi. Can Urol Assoc J. 2015;9(11-12):e837-51. 